\title{
COVID-19 in Southeast Asia
}

\author{
Leila Moradi (iD) ${ }^{1, *}$ \\ ${ }^{1}$ Department of Epidemiology, School of Public Health, Hamadan University of Medical Sciences, Hamadan, Iran \\ "Corresponding author: Department of Epidemiology, School of Public Health, Hamadan University of Medical Sciences, Hamadan, Iran. Email: leilamoradio73@gmail.com
}

Received 2021 July 10; Accepted 2021 August 11.

\begin{abstract}
Background: The emerging disease COVID-19 was first identified in China in late 2019. It soon spread to most countries and continents. The symptoms of this disease range from asymptomatic to severe and fatal. This disease is now an important pandemic and has created an emergency in the world.

Objectives: This study aimed to investigate the epidemiology of COVID-19 in Southeast Asia.

Methods: This ecological study describes the epidemiological features of COVID-19 in southeastern Asia. Data related to identified definite cases and deaths due to this disease along with other information were extracted from the reports of the World Health Organization and imported to SPSS software. The case fatality rate was calculated separately for each country.

Results: The highest number of reported cases of this disease was 30,458,251 in India, and the highest number of death was in this country with 400,312 cases, and the highest mortality rate was in Indonesia with $2.67 \%$.

Conclusions: Using masks and observing social distance and quarantine rules, as well as upgrading diagnostic and laboratory equipment to identify patients, are effective ways to prevent COVID-19 transmission.
\end{abstract}

Keywords: COVID-19, Coronavirus, Southeast Asia

\section{Background}

A severe respiratory illness of unknown origin was reported in Wuhan, China, in late December 2019. Epidemiological studies have shown that the primary source of this disease has been a major seafood market $(1,2)$. The disease spread rapidly to other Chinese provinces and around the world (3). The respiratory disease caused by the coronavirus was later named COVID-19 by the World Health Organization (4). In March 2020, a pandemic of the disease was officially declared by the World Health Organization (5). Most patients had symptoms of fever, cough, and shortness of breath for two to 14 days after exposure to the virus (4). Other symptoms of this disease in mild to moderate cases are loss of smell and taste. However, in some cases of severe disease, the patient needs hospitalization and ventilation support, which potentially leads to death (6). Risk factors for severe COVID-19 are obesity, diabetes, and heart disease. Kidney disease, cancer, and high blood pressure also increase the risk of developing the severe disease (79 ). The pandemic led to quarantine and traffic restrictions, which have had a mixed effect on different economies (10). Today, COVID- 19 is considered a major threat to human health worldwide because it has high infectivity and case fatality rate. Epidemiological models predict that deaths from COVID-19 in densely populated countries could reach as many as one million (11).

\section{Objectives}

This study aimed to describe the epidemiology of COVID-19 in Southeast Asia.

\section{Methods}

The initial data of this study, which included information about the total identified definite cases, total definite deaths due to COVID-19, and the population of the countries, were extracted from the reports of the World Health Organization from the beginning to July 2, 2021, using SPSS 24 software $(12,13)$. Also, the case fatality rate was obtained using the following formula (14): case fatality rate (percent $)=($ No of individuals dying during a specified period after disease onset or diagnosis/of the individuals with the specified disease) $\times 100$.

\section{Results}

The total number of countries in the region was 11 countries according to the World Health Organization clas- 
sification. Data from definitive cases and deaths caused by COVID-19 in the Democratic People's Republic of Korea were not included in the World Health Organization reports. The most populous country in this region is India, with $1,324,171,000$ people, and the least populous country is the Maldives, with 428,000 people. The highest confirmed cases of COVID-19 in this region were in India, with $30,458,251$ cases, and the lowest confirmed cases of COVID19 were related to Bhutan with 2,122 cases. The highest mortality rate was in Indonesia with $2.67 \%$, and the lowest in Bhutan with $0.05 \%$ (Table 1 ).

\section{Discussion}

According to the results of this study, the most definite cases identified in Southeast Asia belonged to the three countries of India, Indonesia, and Bangladesh, in sequence. According to a study by Gupta et al. on COVID19 in India, the expansion of COVID-19 varied from state to state. One of the reasons was the wide latitude in this country. According to the findings of spatial distribution, the transmission of this disease is high in semi-arid and wet provinces, and temperature, rainfall, and more trips to these areas are effective factors in the transmission of the disease in these areas (15). The results of a study by Kumar et al. on COVID-19 in India showed that the high population of this country, which has a high population density, and lack of medical and laboratory equipment, are factors leading to low patient identification and increased transmission rate. Also, the restriction of traffic and the imposition of quarantine will cause great damage to the economy, logistics, and pharmaceutical sectors of this country (16). According to the results of a study by Sutaryono et al., which examined the epidemiology of COVID-19 in Indonesia, the disease was more common in men, and its severe cases occurred mainly in patients with hypertension and diabetes, as well as cardiovascular patients. The country has been on a large scale in reducing disease transmission, implementing health protocols, and social restrictions policies (17). A study by Islam et al., which surveyed COVID-19 in Bangladesh, found that medical equipment in the country was inadequate and there was a shortage of ventilators and diagnostic facilities, as well as quarantine rules and traffic restrictions, and the experience of an economic crisis in addition to the health crisis (18). According to the findings of this study, the COVID-19 pandemic in Southeast Asia has also been associated with high mortality and morbidity, and the only way of preventing is the use of masks and observing the distance. Due to the significant shortage of diagnostic equipment in most countries in the region, it is recommended that the World Health Organization takes effective measures in this regard.

\section{Footnotes}

Authors' Contribution: All steps were performed by L.M. Conflict of Interests: The author declares that there is no conflict of interest.

Ethical Approval: The author agrees to follow the Helsinki Declaration and does not need to obtain permission from the Ethics Committee as it uses secondary data.

Funding/Support: I received no funding or support.

\section{References}

1. Dhar Chowdhury S, Oommen AM. Epidemiology of COVID-19. J Dig Endosc. 2020;11(1):3-7. doi: 10.1055/s-0040-1712187.

2. Li Q, Guan X, Wu P, Wang X, Zhou L, Tong Y, et al. Early transmission dynamics in Wuhan, China, of novel Coronavirus-infected pneumonia. N Engl J Med. 2020;382(13):1199-207. doi: 10.1056/NEJMoa2001316. [PubMed: 31995857]. [PubMed Central: PMC7121484].

3. Dong Y, Mo X, Hu Y, Qi X, Jiang F, Jiang Z, et al. Epidemiology of COVID-19 among children in China. Pediatrics. 2020;145(6). doi: 10.1542/peds.2020-0702. [PubMed: 32179660].

4. McMichael TM, Currie DW, Clark S, Pogosjans S, Kay M, Schwartz NG, et al. Epidemiology of Covid-19 in a long-term care facility in King County, Washington. N Engl J Med. 2020;382(21):2005-11. doi: 10.1056/NEJMoa2005412. [PubMed: 32220208]. [PubMed Central: PMC7121761].

5. Ciotti M, Ciccozzi M, Terrinoni A, Jiang WC, Wang CB, Bernardini S. The COVID-19 pandemic. Crit Rev Clin Lab Sci. 2020;57(6):365-88. doi: 10.1080/10408363.2020.1783198. [PubMed: 32645276].

6. Hyrich KL, Machado PM. Rheumatic disease and COVID-19: Epidemiology and outcomes. Nat Rev Rheumatol. 2021;17(2):71-2. doi: 10.1038/s41584-020-00562-2. [PubMed: 33339986]. [PubMed Central: PMC7747184].

7. Simonnet A, Chetboun M, Poissy J, Raverdy V, Noulette J, Duhamel A, et al. High prevalence of obesity in severe acute respiratory syndrome Coronavirus-2 (SARS-CoV-2) requiring invasive mechanical ventilation. Obesity (Silver Spring). 2020;28(7):1195-9. doi: 10.1002/oby.22831. [PubMed: 32271993]. [PubMed Central: PMC7262326].

8. Sattar N, McInnes IB, McMurray JJV. Obesity is a risk factor for severe COVID-19 infection: Multiple potential mechanisms. Circulation. 2020;142(1):4-6. doi: 10.1161/CIRCULATIONAHA.120.047659. [PubMed: 32320270].

9. Lighter J, Phillips M, Hochman S, Sterling S, Johnson D, Francois $\mathrm{F}$, et al. Obesity in patients younger than 60 years is a risk factor for COVID-19 hospital admission. Clin Infect Dis. 2020;71(15):8967. doi: 10.1093/cid/ciaa415. [PubMed: 32271368]. [PubMed Central: PMC7184372].

10. Donthu N, Gustafsson A. Effects of COVID-19 on business and research. J Bus Res. 2020;117:284-9. doi: 10.1016/j.jbusres.2020.06.008. [PubMed: 32536736]. [PubMed Central: PMC7280091].

11. Goldstein JR, Lee RD. Demographic perspectives on the mortality of COVID-19 and other epidemics. Proc Natl Acad Sci U S A. 2020;117(36):22035-41. doi: 10.1073/pnas.2006392117. [PubMed: 32820077]. [PubMed Central: PMC7486771].

12. World Health Organization. WHO Coronavirus (COVID-19) dashboard. Geneva, Switzerland: World Health Organization; 2021. Available from: https://covid19. who.int/?adgroupsurvey=|protect $\backslash L Y 1 \backslash$ textbraceleftadgroupsurvey $\backslash$ protect $\backslash L Y 1 \backslash$ textbraceright $\&$ gclid $=$ CjwKCAjw7fuJBhBdEiwA21LMYXmHEhyA5oNZq9HQElgBfQ8gr h_zRTc18Mn9Z1ZxLOMmfumncw1LBoCDyUQAvD_BwE. 
Moradi L

\begin{tabular}{lcccc}
\hline Table 1. Frequency Distribution of Identified Definite Cases and Definite Cases of Death and Case Fatality Rates of COVID-19 in Southeast Asia & \\
\hline Country & Population & Total Cases of COVID-19 & Total Deaths of COVID-19 & Case Fatality Rates \\
\hline India & 1324171000 & 30458251 & 400312 & 1.31 \\
\hline Indonesia & 26115000 & 2228938 & 59534 & 2.67 \\
\hline Bangladesh & 162952000 & 930042 & 14778 & 1.59 \\
\hline Nepal & 28983000 & 642053 & 9179 & 1.43 \\
Thailand & 68864000 & 270921 & 2141 & 0.79 \\
\hline Sri Lanka & 20798000 & 260972 & 3063 & 1.17 \\
\hline Myanmar & 52885000 & 161210 & 3364 & 2.09 \\
\hline Maldives & 428000 & 73931 & 213 & 0.29 \\
\hline Timor-Le & 1269000 & 9361 & 24 & 0.26 \\
\hline Bhutan & 798000 & 2122 & 1 & 0.05 \\
\hline
\end{tabular}

13. World Health Organization. Countries. Geneva, Switzerland: World Health Organization; 2021. Available from: https://www.who.int/ southeastasia.

14. Gordis L. Epidemiology. 4th ed. Philadelphia, USA: Saunders; 2008.

15. Gupta A, Banerjee S, Das S. Significance of geographical factors to the COVID-19 outbreak in India. Model Earth Syst Environ. 2020:1-9. doi: 10.1007/s40808-020-00838-2. [PubMed: 32838021]. [PubMed Central: PMC7299143].

16. Kumar SU, Kumar DT, Christopher BP, Doss CGP. The rise and impact of COVID-19 in India. Front Med. 2020;7:250. doi: 10.3389/fmed.2020.00250. [PubMed: 32574338]. [PubMed Central: PMC7256162].

17. Kasjono HS, Andasari SD, Sutaryono S. Diagnosis and epidemiology of Coronavirus (COVID-19) outbreak in Indonesia. J Teknol Laboratorium. 2020;9(1):49-57. doi: 10.29238/teknolabjournal.v9i1.222.

18. Islam S, Islam R, Mannan F, Rahman S, Islam T. COVID-19 pandemic: An analysis of the healthcare, social and economic challenges in Bangladesh. Prog Disaster Sci. 2020;8:100135. doi: 10.1016/j.pdisas.2020.100135. [PubMed: 34173450]. [PubMed Central: PMC7669476]. 